ROHRACHER, H. Methoden zur Regirtrienane und Anmortung der Makrovibrition. Psychologische Betmere, 1960, 4, 118-126.

ROHRACHER, $H$. The biological function of the slphs rhythm. EEG clth Neurophysiol., 1962a, 14, 791.

ROHRACHER, H. Permanente thythmieche Milsobewegungen des Warmbluterogganimus ("mikrovibration"). Die Neturwisenechafien, $1962 \mathrm{~b}, \mathrm{XILX}, 145-150$.

ROHRACHER, H. Comments on a resonance theory of microvibentions. Psychol Rev., 19642, 71, 524-525.

ROHRACUER, H. Microvibration, permaneat muscle cctivity and constancy of body temperature. Percept. mot Skills, 1964b, 19, 198.

ROSNER, B. S. Alpha thythm of the EEG and mechanical properties of brain. Pyychol. Rev., 1961, 68, 359-360.

SCHROCKSNADEL, H., LIENER, A., \& SEMENTTZ, E. Zur biologischen Wirkung milsomechanischer Schwingungen von Intrachallfrequenz. Ber. ges Physiol, 1956, 180, 120.

SUGANO, H. Studies on the microvibration. Kurume Medical J., 1957, 4, 97-113.

SUGANO, H., INANAGA, K. Studies on minor tremor. Japan J. Physio., 1960, 10, 246-257.

TRAVIS, L. E. The relation of voluntary movement to tremors J. exp. Psychol, 1929, 12, 515-524.
VINYCOMB, R. K. Electronic aids to vibration meanurement. J. Britich IRE, 1954, 14, 115-127.

WACHS, H., BRUMLIK, J., \&USHES, B. Studies in Pertineonim: Relationahips between tone and tremor in Partineoniam and in normalk. J. nerv. ment. Dis, 1960,14 .

WACHS, H., \& BUSHES, B. Studies of tremor in normals and in Parkinconim. Arch Neurol, 1961, 4,66.

MLLAMS, J. G. L. A resonance theory of "microvibrations" Pyychol Rev., 1963, 70, 547-558.

WLLLAMS, J. G. L. Use of a resonance technique to measure muxcle ectivity in neurotic and schirophrenic patients. Prychosom. Med., 1964a, 24, 20-28.

WLLIAMS, J. C. L. A resonance theory of "microvibrationa" a reply to Rohracher. Psychol. Rev., 1964b, 71, 526-527.

ZAALBERG van ZELST, J. J. Cincuit for condeneer microphoses with low noise level. Fillips Tech. Rev., 1947/1948, 9, 357-363.

NOTE

1. The author echnowledges the signiticant contributions of Mr. Merrick Troupin, Miss Joyce Bullis, and Mr. Devid Reed. This work would have not been posible without the support of Dr. Thomas Weber.

\title{
The roots of territorial marking in the Mongollan gerbil: A problem of species-common topography
}

\section{D. THIESSEN, UNIVERSITY OF TEXAS, Austin, Texas 78712}

The Mongolian gerbil (Meriones unguiculatus) has recently been introduced into behavioral research. Many features make it an ideal laboratory animal. It is docile, highly exploratory, a good learner, virtually odorless and can be maintained without water; other than that it metabolizes from its food. General characteristics of the gerbil are described, and a brief review of behavioral research is given. The gerbil also possesses unique attributes that can only be studied by matching experimental methodology with species-common responses. Territorial marking is used as example. The gerbil regularly marks objects in an open field by skimming the object with a midventral sebaceous scent gland. The marking and gland are dimorphic, with the male marking about twice as frequently as the female and possessing a gland roughly twice the size. The configuration of the field (object quality/ modifies the frequency of the response, as does the time of day the animals are exposed to the field. Androgen levels control the level of marking in the male and female, and the correlations between testis weight, size of the sebaceous gland, secretory output and marking frequency are significant. When a gerbil is introduced into an open field recently contaminated by another gerbil, or when objects are smeared with sebum and placed in the field, the male tends to be more hesitant in several types of behavior. The laboratony measures are intemally consistent and congruous with the notion that natural selection has acted to reinforce a hormone-behavior relation of social significance to the gerbil.

The Mongolian gerbil (Meriones unguiculatus) is rapidly becoming a significant target for biological research. Most of the work is physiological in character (see Schwentker, 1963), but interest is also focusing on behavior. In our laboratory we have concentrated on three species-common components of gerbil behavior-spontaneous epileptiform seizures found in a propor- tion of the population (Thiessen, Lindzey, \& Friend, 1968), apparent lack of depth perception (Thiessen, Lindzey, Blum, Tucker, \& Friend, 1968) and territorial marking with a ventral sebaceous gland (Thiessen, Friend, \& Lindzey, 1968; Lindzey, Thiessen, \& Tucker, 1968).

The first section of this paper describes various features of the Mongolian gerbil that will be of value to those interested in maintaining and breeding the animal in the laboratory.

The second section describes the marking response and illustrates the effects of altering the configuration of the territory and the circadian phase of testing. The third section gives the relations between marking and other variables and demonstrates the hormone control of the behavior. It also presents an easy technique for measuring the pheromone involved in territorial marking. Last is a discussion of the social and evolutionary significance of marking. Attention is focused throughout on how well the instrumentation of laboratory tactics has elicited species-common reactions of importance to the adaptation of the gerbil.

\section{CHARACTERISTICS OF THE MONGOLIAN GERBIL}

\section{Classification}

The Mongolian gerbil, Meriones unguiculatus, was first described by Milne-Edwards (1867). It is a native of northeast China, eastern Mongolia and Korea. Dr. Victor Schwentker of the West Foundation introduced the gerbil into the United States in 1954. Of the original eleven pairs, five females and four males were induced to breed. Progeny of these matings served as the historical nucleus for most research colonies now in existence. Victor Schwentker at Tumblebrook Farms in Brant Lake, New York, remains the major supplier of research animals.

According to Schwentker $(1963,1968)$ gerbils are classified into 10 and possibly 12 genera. The Mongolian species, unguiculatus, is in the genera Meriones, and is further recognized as part of the subfamily, Gerbillinae, the family, Cricetidae, the 
suborder, Myomorpha, and the order, Rodentia. Cricetidae is the family most represented by laboratory rodents: for example by the Golden Hamster (Mesocricetus auratus), the Chinese Hamster (Cricetelus griseus), the Deer Mouse (Peromysus maniculatus bairdii), the Cotton Rat (Sigmodon Hispidus), the Field Vole (Microtus agrestis), and the Desert Rat (Meriones shawii shawii). All genera of the subfamily, Gerbillinae, are called gerbils, although they are often referred to by their common names of sand rat, desert rat or jird. The wide representation of the gerbil in several genera and its relationship with other members of the family, Cricetidae, enhance its importance in comparative psychological research. Indeed, behavioral work may clear up taxanomic difficulties developing out of morphological studies (Eisenberg, 1967).

\section{General Features}

The Mongolian gerbil has the typical agouti color of many undomesticated rodent species. The dorsal hairs have a white base, a yellow center band and a black tip. The belly is light in color. The average body weights for the adult male and female are given as 90 and $71 \mathrm{~g}$, respectively, while the corresponding birth weights are 3.1 and $2.9 \mathrm{~g}$. In comparison to the mouse and rat, the gerbil has a near invarient coat color and a mid body weight range.

The ontogeny and reproductive features are similar to those of the mouse and rat (Schwentker, 1968). The ears open at five days of age. The incisors erupt at 12 days, and the eye lids open at approximately 20 days. Sexual maturity is reached around 10 to 12 weeks, although the testes may descend by the 35th day and vagina may open at 45 days. In summary the postnatal and prenatal development is slightly slower than for the mouse and rat. This is consistent with the slightly longer gestation period (24 as compared with 21 days).

Litter size varies tremendously, from 1 to 12 , with an average of 4.8. Small litters of one or two are generally ignored by the mother but are rarely canabalized. Breeding may continue up to 20 months and as many as 10 litters have been reported for a single female. This is possible because the female has a postpartum estrus allowing blastula implantations during lactation. Theoretically, then, a gerbil can have a litter every 24 days, although in practice delayed implantation follows postpartum mating, thus extending the gestation period. While the male may take no active part in the care of offspring, it can safely be left with the female throughout the reproductive cycle. The young can be weaned after 21 days.

The estrus cycle of the mature female is highly unpredictable. Marston \& Chang (1965) estimate estrus to occur every four to seven days, and our investigations tend to confirm this estimate. Further domestication may stabilize the cycle, although we suspect that the female may be primarily a reflex ovulator and possess no clear spontaneous cycle.

\section{Laboratory Maintenance}

The gerbil must certainly be one of the easiest rodents to maintain and handle. It needs little water, is clean, nearly odorless and highly curious.

We provide approximately $25 \mathrm{sq}$ in. of floor space per individual. In general it is suggested that the number of square inches corresponds roughly to 5 times the age in weeks for the animals up to seven weeks and 3 times for older animals. Wood shavings in regular mouse or rat cages provide adequate bedding. Combined with "Litter Green," an alfalfa deodorant of considerable merit (McFadden Industries, Inc., Kansas City, Mo.), bedding need be changed only every $11 / 2-2$ weeks.

The gerbil is a natural root and seed eater, al though it survives on a wide variety of foods. Purina mouse and rat pellets provide an adequate diet. Sunflower seeds are a preferred delicacy. The animals can derive all the water they require from the metabolism of foods, especially fats; however, it is our experience that the initial fluid deprivation is so strenuous that it should be avoided. Large amounts of water will be consumed when available $(\overline{\mathrm{X}}=$ $858.1,957.9 \mathrm{ml} / \mathrm{kg} /$ day). High fat diets (over $4 \%$ ) should be avoided with breeding females, as fat pads accummulate around ovaries thus retarding ovulation. Bacterial action in the intestinal tract adds vitamin B to the feces. As this is the only metabolic source of this vitamin the gerbil ordinarily eats about $50 \%$ of its feces (coprophagy). Supplements of vitamin B should be provided for animals living on wire mesh floors which allow fecal boli to fall through.

Gerbils withstand a wide range of environmental variations. We have housed animals at up to $97 \mathrm{deg} F$ for many hours a day for over eight weeks without difficulty. High humidity does not apparently adversely affect gerbils. Brain and endocrine surgery can safely be accomplished under unsterile conditions. Sodium pentobarbital is an excellent anesthetic from which nearly all animals recover. For rapid anesthetization we inject intraperitoneally $.001 \mathrm{ml}$ per $\mathrm{g}$ body weight of a $50 \mathrm{mg}(3 / 4 \mathrm{~g})$ per ml solution. For slower action the solution is diluted by a factor of four and the volume increased by that amount.

Aggression is generally low among groups, hence several can be housed per cage. Eisenberg (1967) refers to the Mongolian gerbil as a "contact" seeker. Isolation tends to increase aggressivity, which in our estimation explains the notion that gerbils are monogomous maters. Often when a mate dies or is removed there is an interval before another mate is provided. Separation for only a short time may increase aggression and disnupt reproduction. The female seems especially quarrelsome. Mating can proceed without difficulty, however, if isolation is not protracted and if pairs are introduced into strange cages simultaneously. Monogamy is probably an artifact of housing conditions.

Gerbils are handled easily by lifting them near the base of the tail. Holding the tail by the end may result in the furred tail sheath slipping off. The Mongolian gerbil is less thigmotaxic than most rodents, hence it is easy to recover from an apparatus or the floor. It displays little fear and can be enticed within reach by tapping the fingers in its vicinity.

Endemic diseases are virtually unknown in this species.

\section{Behavioral Review}

What little work that has been done on Meriones unguiculatus is summarized in Table 1. Almost nothing is known about the normal ecology of this species, except that it is a burrowing form which lives in arid regions of Northeast China. Semi-natural living situations described by Eisenberg (1967) and laboratory investigations only in part reflect the specie's behaviors.

Its docility should be a primary factor in increasing laboratory studies on the gerbil. In general, it seems to be a good learner, especially where aversive reinforcers are used. Visual studies indicate a peculiarity of depth perception and a single report of cochlear potential indicates maximum auditory sensitivity 
Table 1

Summary of Major Behavioral Studies with the Mongolian Gerbil (Meriones unguiculatus)

Behavior
Males mark territories with ventral
sebaceous gland more than females.
Animals exposed to marked territories
more hesitant.

Avoidance conditioning in two-way shuttlebox superior to kangaroo rats but inferior to "mice."

Boice, Boice, \&

Dunham, 1968

"Sandbathing" and area marking with Eisenberg, 1967 perineal drag and ventrum rub. Sociable; many mounts, intromissions and ejaculations per copulatory sequence.

"Paper-shredding" time increases as thicker papers are presented.

Hippocampal lesions increase motor activity and decrease reactivity to novel objects.

Development of territorial marking in male androgen-dependent.

Several behaviors pointed out as appropriate for study in the gerbil.

\section{Less thigmotaxic than "albino rats."}

Nauman, 1968

Self-stimulation for electrical impulses, sex behavior and foot shock are

followed by "foot-stomping."

Territorial marking in adult male dependent on androgen status.

Visual cliff behavior deficient but not brightness discrimination.

Spontaneous seizures related to physiological state, circadian rhythm and stimulus familiarity.

Shock avoidance superior to that of "white rats."

Maze learning retarded in blinded and vibrissaeless animals. Sensory effects additive.

between 3 and $5 \mathrm{Kc} / \mathrm{sec}$. The gerbil is socially oriented and apparently highly territorial. It therefore combines features valuable to a general laboratory rodent with those highly interesting from a species-common viewpoint.

\section{TERRITORIAL MARKING: ITS STIMULUS RELEASE}

\section{Peculiarities of Marking}

Our attention was first drawn to gerbil marking during tests for open field activity. An occasional male was seen to lower its abdomen as it crossed specific regions of a field. A later inspection of the floor revealed that the behavior had been restricted to roughened areas of the wood. At the time we were aware that the ventral surface of the gerbil had a sebaceous gland pad. In a well-developed male the gland is a mid-ventral, orange fusiform pad approximately $3 \mathrm{~cm}$ in length, $0.7 \mathrm{~cm}$ in width, and $0.2 \mathrm{~cm}$ in depth. Its histology has been described, arid its integrity is absolutely dependent on the gonads, at least in the male (Glenn \& Gray, 1965; Mitchell, 1965). The sebum from the gland is oily to the touch and musky in odor. The female also possesses the sebaceous gland, but it is approximately one-half the size of the male's complex. Despite the elegant histological and physiological work the function of the gland has gone unnoticed until recently.

Based on the idea that gerbils mark prominent features of their environment by depositing sebum from the sebaceous gland, several experiments followed in an effort to describe characteristics of the behavior. The most successful measuring device proved to be a gray wooden field one square meter in area and marked off into 16 squares of equal size. A roughened Plexiglas peg. $2.6 \mathrm{~cm}$ in length, $1.2 \mathrm{~cm}$ in width, and $0.7 \mathrm{~cm}$ in height, was positioned at each of the nine lined intersections. Skimming was confined almost entirely to the pegs. The apparatus and behavior are shown in Fig. 1. Data collected to date (Thiessen, Lindzey, \& Blum, 1968) indicate that males adapted to the apparatus mark approximately 14 times during a 5-min test and females mark about seven times in the same period. The sex difference in marking corresponds roughly to the difference in gland size.

\section{Peg Characteristics}

Our initial studies paid no attention to the stimulus value of the pegs, but since some animals never marked, or marked infrequently, it became important to determine if the variation was in some way related to the configuration of the pegs. Thus, seven different sets of pegs (nine to a set), or a combination of these, were used in the usual apparatus to test marking frequency of eight male gerbils approximately 120 days of age. All pegs were wooden and were $0.7 \mathrm{~cm}$ in height, and most were $2.6 \mathrm{~cm}$ in length, and $1.2 \mathrm{~cm}$ in width. Otherwise the pegs varied in the following ways: one set was of the size generally used; the other sets were either notched at the top and sides, $5.0 \mathrm{~cm}$ square, flat but circular, round and convex, or reduced to $0.35 \mathrm{~cm}$ in height, respectively. Thus the test pegs can be described as high, regular, irregular, wide, round-flat, convex, and low.

All animals were pretested $4 \mathrm{~min}$ daily for five consecutive days on the regular pegs, and then tested in two phases. In Phase 1 each gerbil was assigned an order of daily peg presentation so that no two had the same sequence. The animals were tested for $4 \mathrm{~min}$ a day until all eight peg configurations (including one day of a random assortment of pegs) were presented. The order of presentation was then reversed and the animals tested over the sequence again. The two scores that each gerbil received for each peg pattern were averaged. In Phase 2, beginning one week later, the high and wide pegs were presented simultaneously (four of each kind) to each gerbil for $4 \mathrm{~min}$ on each of four days. The arrangement of pegs in the apparatus was varied every day to prevent a marking position bias. Each animal received an average score on each of the types of pegs for the total of four trials.

Table 2 gives the results for the two phases. In Phase 1 there appeared a preference hierarchy in favor of pegs that can be abstractly described as high, smooth on the surface and narrow in width. The differences, however, did not reach statistical 

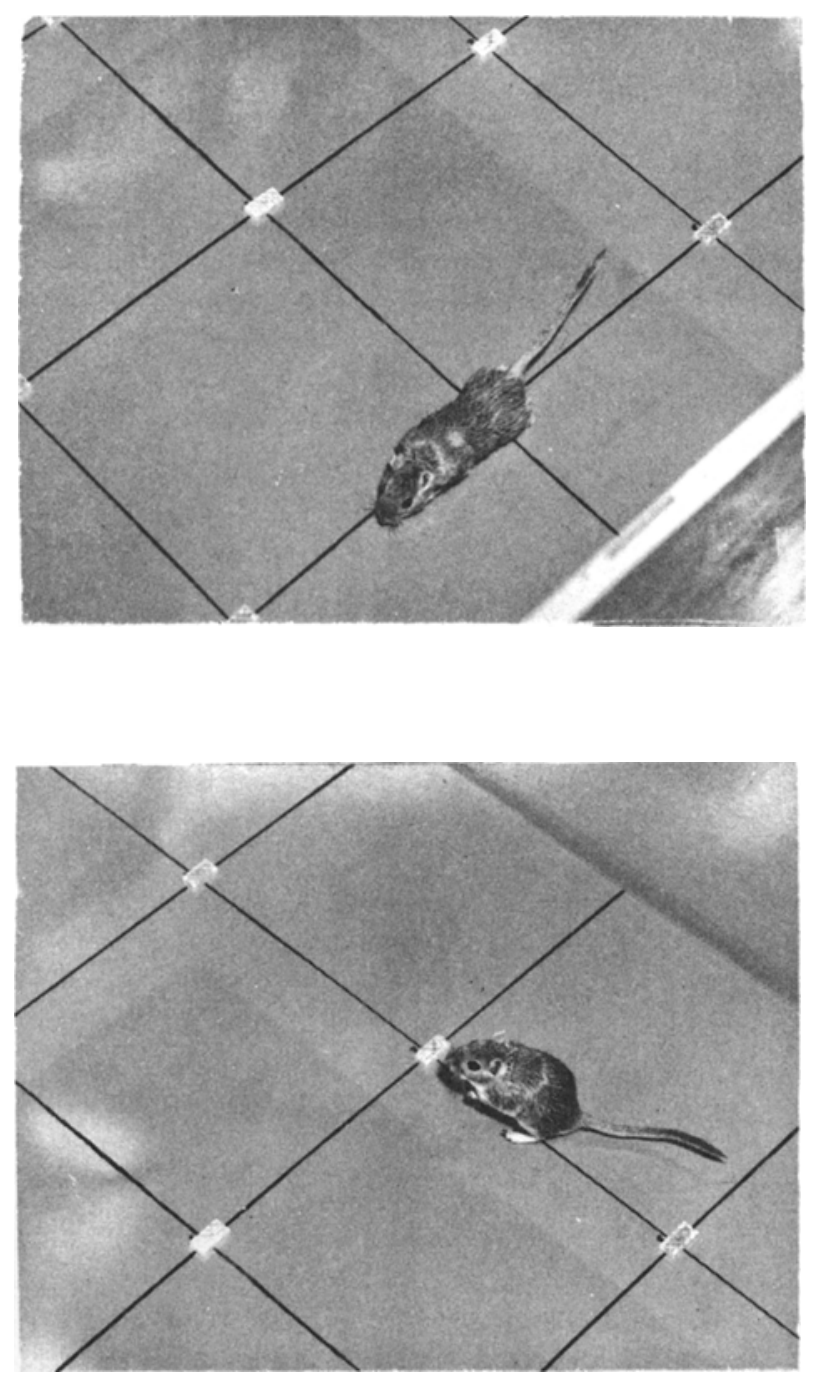

Fig. 1. Major phases of marking: approach (upper) and marking (lower).

Table 2

Frequency of Marking Various Shaped Pegs $(4 \mathrm{~min}$ tests)

\begin{tabular}{|c|c|c|}
\hline $\begin{array}{c}\text { Peg } \\
\text { Characteristic } \\
\end{array}$ & $\begin{array}{c}\text { Phase } 1 \\
\overline{\mathrm{X}} \text { No. Marks } \\
\end{array}$ & $\begin{array}{c}\text { Phase } 2 \\
\overline{\mathrm{X}} \text { No. Marks }\end{array}$ \\
\hline High & 11.1 & 8.1 \\
\hline Regular & 10.3 & \\
\hline Low & 10.2 & \\
\hline Combination & 9.8 & \\
\hline Convex & 9.3 & \\
\hline Irregular & 8.8 & \\
\hline Round-Flat & 8.6 & \\
\hline Wide & 6.8 & 3.9 \\
\hline
\end{tabular}

significance. In Phase 2, where only the high and wide pegs receiving the most extreme responses in Phase 1 were compared, the high pegs were again preferred $(t=3.48 ; d f=7 ; p<.02)$.

The configuration of the environment is obviously of relevance to the gerbil in its marking behavior. The best performance can be elicited by high pegs that have a long smooth axis. Gerbils mark most frequently along the linear axis, perhaps allowing the most secretion to be layed down from a correspondingly long gland. In spite of preference for objects, the rank order difference among the eight individuals remained fairly constant regardless of the shape of the peg or the absolute levels of marking. The coefficient of concordance (W) for Phase 1, indicating the degree of consistency of individual differences, was $.87(p<.001)$. The correlation for Phase 2 between high and low pegs suggested the same dependence $(r=.53 ; \mathrm{df}=6)$. Apparently the relative difference between animals persists under a variety of conditions.

\section{Time of Day}

Our experience has been that gerbils are nocturnal in activity (Thiessen, Lindzey, \& Blum, 1968). We supposed, therefore, that social activities such as marking would be more pronounced during the dark period. Two groups of 10 gerbils were tested for marking during the day and night phases of a $12 \mathrm{~h}$ on, $12 \mathrm{~h}$ off light cycle in a counterbalanced order.

The results for both groups clearly indicate that marking is higher at night than during the day. The first group scores were $\bar{X}$ $=2.4 \pm 1.40$ and $\bar{X}=7.7 \pm 1.41$ for the day-night marking, respectively $(t=3.19 ; p<.02)$. The comparable scores for the second group were $\bar{X}=1.5 \pm 0.51$ and $10.1 \pm 2.73$ for the light and dark phases $(t=3.17 ; p<.02)$. In other words, marking is from three to seven times more frequent at night. The order of testing, that is, day followed by night or night followed by day, had no obvious influence on the results.

Three conclusions seem evident from the observations presented in this section: (1) sex differences are a prominent feature of marking territories, (2) physical changes of objects in the territory can influence the rate of marking; however, individual differences are recognizable under all conditions, and (3) the phase of the day-night cycle has a significant influence on frequency of marking. All three variations seem to reflect basic features of territorial reaction in the Mongolian gerbil, and suggest how future studies should be conducted. Of the three factors discussed (sex differences, object quality, and nocturnal variations) object quality appears to be the least important.

\section{THE CONTROL MECHANISMS OF MARKING}

\section{The Androgen Basis in the Male Gerbil}

Several lines of evidence strongly suggest that the controlling influence for territorial marking in the male gerbil is androgen (the same may be true for the female). The sebaceous pad, for one thing, regresses in the absence of the testes but reappears with androgen replacement therapy (Glenn \& Gray, 1965; Mitchell, 1965). Second, the regression and reappearance of the gland following castration and subsequent injection of testosterone propionate parallels a sharp fall and elevation of the skimming activity (Thiessen, Friend, \& Lindzey, 1968). Moreover, the testes must be present for the normal development of both the gland and the marking, and the onset of the behavior and growth of the gland are facilitated by supplements of testosterone propionate (Lindzey, Thiessen, \& Tucker, 1968).

Although endocrine extirpation and hormone replacement are the classic ways to verify a hormone-behavior relation, the techniques do not necessarily corroborate the association with the usual range of variation. Perhaps only a minimal amount of 
androgen is sufficient to allow the basic expression of marking, while deviations around this base level depend entirely on other factors. This does not appear to be the case for at least two reasons. First, as the above reports demonstrate, large doses of testosterone propionate create precocious and "super" markers -the effects appear dose dependent as well. Therefore, above threshold levels of hormone can elevate marking. Second, correlations indicate that testis weight, gland size and marking are significantly related. Relevant data are given in Table 3 . They are taken from 114 male gerbils tested for marking over 12 consecutive $4 \mathrm{~min}$ periods, one test every third day. General activity was observed during the same tests and was recorded as the number of lines crossed during the $4 \mathrm{~min}$. The average scores for the last four trials were used for the calculations of correlations appearing in Table 3. Testis weight was obtained by sacrificing the animals immediately following the last test day.

Table 3

Correlations Among Variables in Intact Male Gerbils (df = 112)

\begin{tabular}{|c|c|c|c|c|}
\hline Measure & $\begin{array}{l}\text { Testis } \\
\text { Weight }\end{array}$ & Marking & $\begin{array}{l}\text { General } \\
\text { Activity }\end{array}$ & $\begin{array}{r}\text { Body } \\
\text { Weight }\end{array}$ \\
\hline \multicolumn{5}{|l|}{ Sebaceous } \\
\hline Gland Size & $.28 *$ & $.22 *$ & .05 & $.36 * *$ \\
\hline & $.36^{* *}$ & -.08 & $.54 * *$ \\
\hline \multicolumn{2}{|c|}{ Marking } & & $-.28 * *$ & .15 \\
\hline \multicolumn{3}{|c|}{ General Activity } & & .10 \\
\hline
\end{tabular}

The results indicate low but significant correlations among several variables of interest. The most relevant triad of correlations is the relation between testis weight, gland size and marking. Testis weight may to some degree reflect normal variations in androgen secretion, and hence normal variations in sebaceous gland size and marking. The correlational data, while not conclusive in meaning, are very much in accord with the extirpation and replacement studies cited earlier and lend support to the notion that territorial marking within the usual range is androgen dependent.

\section{The Hormone Basis in the Female Gerbil}

It is less certain that androgen is the critical hormone underlying marking in the female, although some evidence points in that direction. In the preliminary investigation described here, testosterone, but not estrogen or progesterone, was able to increase both gland size and marking in intact females. The general anabolic hormone, somatotropin, was without effect.

Measurements were extended to include a direct index of sebaceous gland secretion. Secretory activity was assessed by blotting the gland with a preweighed filter paper strip. The strip was dipped in $70 \%$ alcohol, rubbed across the gland with three even strokes, dried in front of a fan for 2-min and then reweighed. The difference in pre- and postweights was due to glandular sebum. The orangish-brown sebum left on the paper was additionally rated for density from 1 to 5 , with 1 indicating no secretion and 5 indicating heavy secretion.

For the attempt to alter female marking with hormones, 60 adults approximately 100 days of age were divided into five conditions and injected with various hormones or a vehicle solution. Each group received three weeks of priming injections (two a week) followed by four weekly 5 min tests in a marking field. Injections were continued twice a week throughout testing, and were scheduled not to occur on days of testing. The five respective groups received the following injections subcutaneously in $0.1 \mathrm{ml}$ vehicle of safflower oil: (1) vehicle only, (2) $640 \mu \mathrm{g}$ testosterone propionate, (3) $80 \mu \mathrm{g}$ estradol benzoate, (4) $800 \mu \mathrm{g}$ progesterone, and (5) $1.5 \mathrm{IU}$ somatotropin. The measurements taken at each weekly test period were: frequency of marking, general activity, defecation, urination, gland size (length $x$ width in $\mathrm{cm}$ ), secretory output of the marking gland (blot) and body weight. The average scores for variables showing significant hormone differences are shown in Table 4.

Testosterone was the only hormone tested that significantly modified the measures-marking, gland size, gland secretion and defecation were all increased by testosterone injections. Regardless of hormone condition, there was a strong correlation between marking, gland size, secretory weight and rating of secretory density. Table 5 indicates the extent of these relations, while Fig. 2 shows typical hormone influences on the density of the secretory material left on the filter paper strips.

Clearly, testosterone is effective in regulating marking frequency and gland secretion. The two primary female sex hormones, estrogen and progesterone, are not; neither is somatotropin, a general growth hormone. Whether or not androgen normally controls the response in females is by no means established; however, the evidence is suggestive. Assuming that androgen is important, its origins could be the ovaries or the adrenals. Ovariectomy, we have found, leads to comple te atrophy of the sebaceous complex in a matter of weeks (unpublished), indicating a singular importance of the gonads in both sexes.

Table 4

Effects of Hormone Supplements on Territorial Responses of the Female Gerbil $(\mathrm{df}=4 \& 55)$

\begin{tabular}{lcccc}
\hline $\begin{array}{l}\text { Hormone } \\
\text { Condition }\end{array}$ & $\begin{array}{c}\text { Marking Frequency } \\
\overline{\mathbf{X}} \text { Marks } / 5 \mathrm{~min}\end{array}$ & $\begin{array}{c}\overline{\mathrm{X}} \text { Gland Size in cm } \\
\text { Length } \mathrm{x} \text { Width }\end{array}$ & $\begin{array}{c}\text { Gland Secretion } \\
\overline{\mathrm{X}} \text { Wt of Blot in } \mathrm{mg}\end{array}$ & $\begin{array}{c}\text { Defecation } \\
\overline{\mathrm{X}} \text { Boli/5 } \mathrm{min}\end{array}$ \\
\hline Vehicle & $5.00 \pm 2.91$ & $0.605 \pm 0.073$ & $1.94 \pm 0.24$ & $3.08 \pm 1.16$ \\
Testosterone & $25.17 \pm 3.15$ & $1.069 \pm 0.049$ & $3.55 \pm 0.45$ & $7.42 \pm 1.28$ \\
Estrogen & $3.67 \pm 1.53$ & $0.641 \pm 0.070$ & $2.42 \pm 0.37$ & $5.83 \pm 1.55$ \\
Progesterone & $0.42 \pm 0.34$ & $0.577 \pm 0.033$ & $1.89 \pm 0.24$ & $2.42 \pm 1.14$ \\
Somatotropin & $2.25 \pm 1.35$ & $0.651 \pm 0.060$ & $2.41 \pm 0.04$ & $5.92 \pm 1.20$ \\
\hline F tests* & $22.63 ; \mathrm{p}<.001$ & $11.97 ; \mathrm{p}<.001$ & $3.63 ; \mathrm{p}<.05$ & $2.72 ; \mathrm{p}<.05$ \\
\hline
\end{tabular}


Table 5

Relations Between Average Frequency of Marking in 5 Min and Different Measures of Gland Activity

\begin{tabular}{|c|c|c|c|c|c|c|c|c|}
\hline $\begin{array}{c}\text { Density of } \\
\text { Smear }\end{array}$ & $\mathrm{N}^{*}$ & $\overline{\mathrm{X}}$ Marks & $\begin{array}{l}\text { Weight of } \\
\text { Smear (mg) }\end{array}$ & $\mathbf{N}$ & $\overline{\mathrm{X}}$ Marks & $\begin{array}{l}\text { Sebaceous } \\
\text { Gland Size } \\
(1 \mathrm{xw} \text { in } \mathrm{cm})\end{array}$ & $\mathbf{N}$ & $\overline{\mathrm{X}}$ Marks \\
\hline 1 & 19 & 1.8 & $0.0-1.0$ & 7 & 1.0 & $0.00-0.40$ & 3 & 0 \\
\hline 2 & 14 & 0.8 & $1.1-2.0$ & 17 & 6.9 & $0.41-0.60$ & 24 & 0.75 \\
\hline 3 & 10 & 10.8 & $2.1-3.0$ & 21 & 5.0 & $0.61-0.80$ & 16 & 3.30 \\
\hline 4 & 5 & 12.8 & $3.1-4.0$ & 8 & 8.5 & $0.81-1.00$ & 8 & 18.90 \\
\hline 5 & 10 & 21.4 & 4.1 \& over & 7 & 19.7 & $1.01 \&$ above & 9 & 24.00 \\
\hline
\end{tabular}

* Two smears lost

\section{SOCLAL AND EVOLUTIONARY SIGNIFICANCE OF TERRITORIAL MARKING IN THE MONGOLIAN GERBIL}

Marking will remain a laboratory curiosity until its social significance is defined. Scent glands can have many functions and they need not be confined to the establishment of territories. They can be used to aggregate conspecifics, disperse members of a population, alarm or arouse groups or individuals, attract members of the opposite sex, afford cues for individual recognition and reflect social status (Marler \& Hamilton, 1966). The marking of objects by the gerbil suggests that territorial signaling is of predominant importance; however, other functions are not excluded. Chemical communication in the gerbil may turn out to have a broad band of effects divisible into independent social functions.

Initial work indicates that marking can affect the behavior of

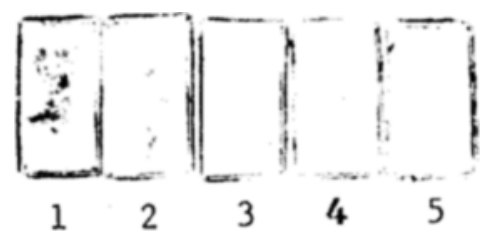

Fig. 2. Density of sebum obtained by blotting sebaceous gland with filter strips. One through five are blots from gerbils receiving (1) testosterone, (2) safflower oil, (3) somatotropin, (4) estrogen, and (5) progesterone.

others that migrate into the area (Thiessen, Lindzey, \& Blum, 1968). When a male enters a field previously contaminated by another animal, $88 \%$ of its responses are depressed. The responses include marking, sniffing of pegs, general activity, defecation and urination. The female is much less affected; the comparable depression of activities reaches only $58 \%$. The sebum left on pegs is a very potent olfactory stimulus. When pegs masked with sebum are placed in a clean apparatus the activity of naive male gerbils is reduced (unpublished observations of Stephen Blum). The tests thus far show that the tendency is for males to become more hesitant in a field previously occupied by another animal.
Females seem unaffected. Apparently the sebum acts as a chemical signal to avert territorial onslaughts. However, too little is known about the behavior and ecology of the gerbil to permit generalizations at this time.

Ordinarily androgen is conceived of as primarily a sex hormone, and indeed the association is strong (Beach, 1965). However, the same hormone may also control aggression (e.g., Ulrich, 1966), and in the case of the gerbil, territorial signaling. The gerbil may represent an interesting species in which androgen regulates all three functions-sex behavior, aggression and territorial signaling.

The study of marking is of experimental as well as theoretical advantage. The response is discrete and easily measured. Unlike sex or aggressive behavior, its measurement need not be complicated by the presence of another animal. Moreover, the gland offers an external index of androgen level and is thus of great value as a biological referent. Our studies indicate that the secretory level can be directly ascertained with a minimum of effort by blotting the sebum found on the gland. This technique may lead to the development of a reliable bioassay of androgen level. Last, the gerbil can become a model of comparison for the species-common responses related to territoriality. Several species possess organized external gland complexes that excrete odorous chemicals into the environment, and in a few species behavioral correlates are know (e.g., Eppel \& Lorenz, 1967; Pearson, 1946; Mykytowycz, 1965). With the recent assurgence of exocrinology (Parkes \& Bruce, 1961) and attention to odorous pheromones (Marler \& Hamilton, 1966), exhaustive observations on a number of related species will be important. With increasing effort we may be able to mollify Beach's (1950) admonishment that approximately $50 \%$ of all behavioral experiments have been conducted on one one-thousandth of one per cent of all extant species.

\section{REFERENCES}

BEACH, F. A. The snark was a Boojum. Amer. Psychol, 1950, 5, 115-124. BEACH, F. A. (Ed.), Sex and behavior. New York: Wiley, 1965.

BLUM, S. L., \& THIESSEN, D. D. A territorial marking response in the gerbil (Meriones unguiculatus). Paper read at Southwestern Psychological Association, New OHeans, La., 1968.

BOICE, R., BOICE, C., \& DUNHAM, A. E. Role of docility in avoidance: Gerbils and kangaroo rats in a shuttlebox. Psychon. Sci, 1968, 10, 381-382.

EISENBERG, J. F. A comparative study in rodent ethology with emphasis on evolution of social behavior, 1. Procedures United States National Museum, 1967, 122, 1-51.

EPPLE, G., \& LORENZ, R. Vorkommen, Morphologie und Funktion der Sternaldruse bei den Platymhini. Folia Primatology, 1967, 7, 98-126.

FINCK, A., \& SOFOUGLU, M. Auditory sensitivity of the Mongolian gerbil (Meriones unguiculatus). J. Aud. Res, 1966, 6, 313-319.

FRIEND, H. C., THIESSEN, D. D., \& LINDZEY, G. Spontaneous seizures in the gerbil. Paper read at Southwestern Psychological Association, Houston, Texas, 1967. 
GLENN, E, M., \& GRAY, J. Effect of various hormones on the growth and histology of the gerbil (Meriones unguiculatus) abdominal sebaceous gland pad, Endocrinology, 1965, 76, 1115-1123.

GLICKMAN, S. E., FRIEND, L., \& MORRISON, B. A. Shredding of nesting material in the Mongolian getbil. Percept. mot. Skills, 1967, 24, $473-474$.

HIGGINS, T., GLICKMAN, S. E., \& ISAACSON, R. The effects of hippocampal lesions on behavior patterns of the Mongolian gerbil (Meriones unguiculatus), Psychon. Bull., 1967, 1, 26.

LINDZEY, G., THIESSEN, D. D., \& TUCKER, A. Development and hormone control of territorial marking in the male Mongolian gerbil (Meriones unguiculatus). Developm. Psychobiol., 1968, in press.

MARLER, P. R., \& HAMILTON, W. J. III. Mechanisms of animal behavior. New York: Wiley, 1966.

MARSTON, J. H., \& CHANG, M. C. The breeding, management and reproductive physiology of the Mongolian gerbil (Meriones unguiculatus). Lab. Anim Care, 1965, 15, 34-48.

MILNE-EDWARDS, A. Observations sur quelques mammifers du Nond de la Chine, Ann. Sci Naturalist (Zool.), 1867, 7, 375-377.

MITCHELL, O. G. Effect of castration and transplantation on ventral gland of the gerbil. Proc. Soc. Exp. biol. Med., 1965, 119, 953-955.

MITCHELL, O. G. The supposed role of the gerbil ventral gland in reproduction. J. Mammal., 1967, 48, 142.

MYKYTOWYCZ, R. Further observations on the territorial function and histology of the submandibular cutaneous (chin) glands in the rabbit, Oryctolagus cunicular (L.). Anim. Behov., 1965, 13, 400-412.

NAUMAN, D. J. The Mongolian gerbil as an experimental animal in behavioral research. Paper read at North and South Dakota Bi-State Psychological Convention, Aberdeen, South Dakota, 1963.

NAUMAN, D. J. Open field behavior of the Mongolian gerbil. Psychon. Sci, 1968, 10, 163-164.
PARKES, A. S., BRUCE, H. M. Olfactory stimuli in mammalian reproduction. Science, 1961, 134, $1049-1054$.

PEARSON, O. P. Scent glands of the short-tailed shrew. Anat. Rec., 1946, 94, 615-629.

ROUTTENBERG, A., \& DRAMIS, R. C. "Foot-stomping" in the gerbi: rewarding brain stimulation, sexual behaviour, and foot shock. Nature, $1967,214,173-174$.

SCHWENTKER, V. The gerbil-a new laboratory animal, minois Vet, $1963,6,5-9$.

SCHWENTKER, V. The gerbil: an annotated bibliography. Available from Tumblebrook Farm, Inc., Brant Lake, New York, 1968.

THIESSEN, D. D., LINDZEY, G., BLUM, S., TUCKER, A., \& FRIEND, H. Visual behavior of the Mongolian gerbil (Meriones unguiculatus). Psychon. Sci, 1968, 11, 23-24.

THIESSEN, D. D., FRIEND, H., \& LINDZEY, G. Androgen control of territorial marking in the Mongolian gerbil. Science, 1968, 160, $432-434$. $432-434$.

ULRICH, R. Pain as a cause of aggression. Amer. Zoologist, 1966, 6, 643-662.

WALTERS, G. C., PEARL, J., \& ROGERS, J. V. The gerbil as a subject in behavioral research. Psychol. Rep., 1963, 12, 315-318.

WEBSTER, D. B., \& CACCAVALE, K. L. Roles of eyes and vibrissae in maze running behavior of gerbils and kangaroo rats. Amer. Zoologist, $1966,6,23$

\section{NO'TE}

1. This work was supported by Grant MH 1407-01 and Research Development Award, MH 11, 174-01, from the National Institute of Mental Health.

\section{An improved shocking surface for pigeons and rats'}

\section{JOSEPH J. WALKER AND M. E. BITTERMAN, BRYN MAWR COLLEGE, Bryn Mawr, Pa.}

$A$ resistive shocking surface and an appropriate power supply are described. The efficacy of the system is illustrated with some data on the activity of pigeons and rats as a function of the voltage applied.

The conventional shocking grid is unsuitable for the pigeon because when the bars are far enough apart to prevent shorting by fecal material the animal can avoid shock by standing on a single bar. Wing clips are irritative and do not make dependable contact with the skin. Subdermal electrodes are difficult to implant properly, and the internal leads to them are easily broken off in the course of activity. In work with the rat, the conventional grid is reasonably satisfactory if used with a scrambler to eliminate the possibility that the animal can stand on two equipotential bars, but the animal still can avoid shock by rearing up on a single bar. The attachment of shocking electrodes to the skin is more difficult for rats than for pigeons.

An earlier report from this laboratory describes a resistive shocking technique suitable both for pigeons and for rats (Longo, Holland, \& Bitterman, 1960). The principle is simple: when a voltage is applied across a resistive surface on which an animal is standing, the animal is connected in parallel with the circuit through the surface. The results reported in the earlier paper were obtained with painted surfaces into which holes were drilled to permit the running off of urine and feces. The resistive paints used were made by adding powdered graphite to a binder such as black asphaltum or a solution of styrofoam in methyl-ethylketone. Such surfaces are easy to construct, but they are unsatisfactory because their resistance changes with continued use, both as a function of cleaning and as a function of current flow. Pending the development of a suitable paint, we now use a more elaborate surface, somewhat difficult to construct, but perfectly stable.

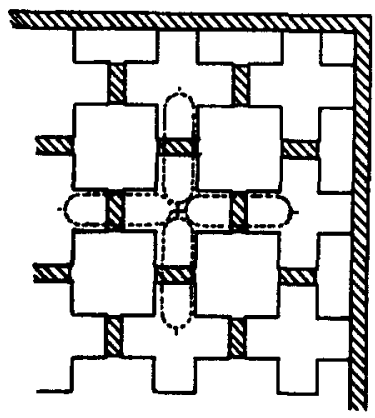

Fig. 1. A section of the shocking surface. Above: top view. The hatched areas are plastic dividers and border pieces; the crosses are brass electrodes; the squares are openings which permit the running off of urine and feces; the broken lines show the ceramic resistors wired to the crosses on the under side. Below: side view showing crosses, dividers, and resistors.

Diagrammed in Fig. 1 is a section of the $103 / 4 \times 91 / 2$-in. surface for which data are reported here. The surface is a $19 \times 17$ matrix of $1 / 2$-in. brass crosses (arms $3 / 32$ in. wide) separated by $1 / 16$-in. plastic dividers. The thickness of the surface is $1 / 2$ in. On the under side, each cross is connected to each adjacent cross by a $15 \mathrm{~K}$, $5 \%, 1 / 2-W$ ceramic resistor, and the properties of the network are such that the resistance between adjacent crosses is about $4 \mathrm{~K}$. 